Research Article

\title{
Assessment of antioxidant activity of metformin in ethanol induced liver damage in Sprague Dawley rats
}

\author{
Kanchan Dnyanesh Borole ${ }^{1}$, Pradnya Hemant Padalkar $^{2}$, Ravi Swami ${ }^{3}$
}

\begin{abstract}
${ }^{1}$ Department of Pharmacology, Bharati Vidyapeeth Deemed University Medical College, Pune, Maharashtra, India, ${ }^{2}$ Department of Biochemistry, Bharati Vidyapeeth Deemed University Medical College, Pune, Maharashtra, India, ${ }^{3}$ Department of Pathology, Bharati Vidyapeeth Deemed University Medical College, Pune, Maharashtra, India
\end{abstract}

Received: 11 January 2016 Accepted: 12 February 2016

\section{*Correspondence to:}

Dr. Kanchan D. Borole, Email: kanchan.brl@gmail.com

Copyright: (C) the author(s), publisher and licensee Medip Academy. This is an openaccess article distributed under the terms of the Creative Commons Attribution NonCommercial License, which permits unrestricted noncommercial use, distribution, and reproduction in any medium, provided the original work is properly cited.

\begin{abstract}
Background: Alcoholic liver disease (ALD) is a life style associated and one of the most common causes of chronic liver disease in the world. Chronic and excessive ethanol consumption impairs fatty acid oxidation and thereby stimulates lipogenesis, which leads to steatosis. Manifestation of harmful effects by alcohol occurs by free radical species which react with most of the cell components by changing their structures and functions. The hepatoprotective activity of metformin may be due to its antioxidant effect and enhancing fatty acid oxidation. So the aim of the present study is to evaluate preventive hepatoprotective effect of metformin in terms of hepatic oxidative stress marker enzymes and liver-histopathology scores.
\end{abstract}

Methods: Thirty adult Sprague Dawley rats of either sex, weighing 200-250 g were selected for the study. The study was performed as per CPCSEA guidelines. The rats were randomly divided into 5 groups; $n=6$. All the treatments were given once a day for 21 days. After day 21, the dissected liver was used to assess oxidative stress marker enzymes malondialdehyde (MDA), superoxide dismutase (SOD), catalase (CAT) spectrophotometrically. The liver damage was assessed by histopathological scoring (HPS).

Results: A comparison of The liver tissue MDA, SOD, CAT levels (nmol/g) and HPS value in the various groups on day-22 suggests that a treatment with metformin at low dose displayed a minimal hepatocellular protection when compared to that of the ethanol-treated and vehicle treated groups; however, metformin treatment at moderate and high doses elicited a better hepato protection as compared to low dose metformin treated groups. A dosedependent hepatoprotection by metformin that high-dose metformin may be a potential therapeutic candidate in attenuating the ALD.

Conclusions: Metformin co-administration effectively prevented hepatic damage caused by ethanol in animal model with favourable modification in the oxidative stress marker enzymes in liver tissue and histopathology. It may be effective for preventing liver toxicity in chronic alcoholics. A dose dependent hepatoprotection reveals that metformin may be a potential therapeutic candidate in attenuating the ALD which needs a systematic clinical study.

Keywords: ALD, Metformin, MDA, SOD, Catalase, Histopathological scoring

\section{INTRODUCTION}

Alcoholic liver disease (ALD) is a life style associated and includes a wide spectrum of injury, ranging from simple steatosis to frank cirrhosis. It may well represent the oldest form of liver injury known to mankind. ${ }^{1,2}$

Manifestation of harmful effects by alcohol occurs by free radical species which react with most of the cell components by changing their structures and functions. In ALD accumulation of fat and inflammation in the liver are the main pathological features which tend to liver cirrhosis and hepatocellular carcinoma if alcohol consumption is not stopped. The development of steatohepatitis is major factor in the progression to cirrhosis. ${ }^{3}$ Chronic and excessive ethanol consumption impairs fatty acid oxidation and thereby stimulates lipogenesis, which leads to steatosis. ${ }^{2}$ Accumulation of fat in the liver tends to increase the sensitivity of the liver to the second hit that leads to inflammatory liver cell damage. ${ }^{4}$ Oxidative stress, endotoxins, and cytokines are considered to be the 
causes of the second hit and are related to the pathogenesis of ALD.

The severity of liver damage related to alcohol varies among different individuals and sometimes within individual at different times. The therapy of ALD varies according to the severity of liver damage and clinical condition of an individual.

Though pathophysiology of ALD known, a successful therapeutic approach to prevent or reverse ALD is rare. Conventional therapy is based on general supportive and symptomatic care. ${ }^{1}$ Few synthetic molecules are still under pipeline and are being probed for their utility in ALD. ${ }^{4,5}$ Therefore, a potential candidate beneficial in ALD is still enduring. ${ }^{6}$

The hepatoprotective activity of metformin may be due to its antioxidant effect and enhancing fatty acid oxidation. Also it is suggested that metformin may cause down regulation of TNF $\alpha$ mediated signaling and activation of AMP-Kinase (AMPK). Furthermore, ALD is having strong association with insulin resistance and metformin tends to decrease insulin resistance as well as decrease oxidative stress. Therefore, metformin was thought to be useful in ALD.

So the aim of the present study was to evaluate preventive hepatoprotective effect of metformin in terms of hepatic oxidative stress marker enzymes and liverhistopathology scores.

\section{METHODS}

\section{Drugs and chemicals}

Metformin hydrochloride was procured from Glenmark Pharmaceuticals Ltd., Andheri (East) Mumbai and ethanol GR grade, $99.8 \%$ pure Mfg by Merck (Germany) and was purchased from M/S Sharad Agencies, Pune. Ethanol was diluted with distilled water to get $40 \% \mathrm{v} / \mathrm{v}$ concentration. Ethanol was administered in the dose of $1 \mathrm{ml} / 100 \mathrm{~g} / \mathrm{d}$ orally.

\section{Animals}

Thirty adult Sprague Dawley rats of either sex, weighing 200-250 g were selected for the study. The study was conducted after approval of Institutional Animal Ethics Committee (CPCSEA Reg. No.258/2009) in central animal house, Bharati Vidyapeeth Deemed University Medical College, Pune, India. The animals were housed in plastic cages under controlled conditions of 12-h light $/ 12-\mathrm{h}$ dark cycle, $50 \%$ humidity and at $25^{\circ} \mathrm{C}$. They all received a standard pelleted diet (Pranav Agro Industries Ltd., Pune, Maharashtra, India) and water $a d$ libitum. The study was performed as per CPCSEA guidelines.

\section{Experimental design}

For three doses of metformin; low, moderate and high, three different solutions of different strengths were prepared as follows and were administered $1 \mathrm{ml} / 100 \mathrm{~g}$ orally.
- 125 (low dose) mg/kg/d orally (Met-1) - 12.5 mg/ml.

- 250 (moderate dose) $\mathrm{mg} / \mathrm{kg} / \mathrm{d}$ orally (Met-2) - 25.0 $\mathrm{mg} / \mathrm{ml}$.

- 500 (high dose) $\mathrm{mg} / \mathrm{kg} / \mathrm{d}$ orally (Met-3) - 50.0 $\mathrm{mg} / \mathrm{ml}$.

Table 1: Groups and drug treatments.

\begin{tabular}{|c|c|c|c|}
\hline Groups & Treatments & Symbol & Dose p. o. \\
\hline $\begin{array}{l}\text { Group } \\
1\end{array}$ & $\begin{array}{l}\text { Ethanol } 40 \% \mathrm{v} / \mathrm{v} \\
\text { in water (Day } 1- \\
21 \text { ) }\end{array}$ & $\mathrm{E}$ & $\begin{array}{l}1 \mathrm{ml} / 100 \mathrm{~g} / \mathrm{d} \text {, } \\
\text { oral gavage } \\
\text { [po] }\end{array}$ \\
\hline $\begin{array}{l}\text { Group } \\
2\end{array}$ & $\begin{array}{l}\text { Ethanol + } \\
\text { Distilled water } \\
\text { (Vehicle for } \\
\text { Metformin) (Day } \\
1-21 \text { ) }\end{array}$ & E+DW & $\begin{array}{l}1 \mathrm{ml} / 100 \mathrm{~g} / \mathrm{d} \text {, } \\
\text { oral gavage } \\
\text { [po] }\end{array}$ \\
\hline $\begin{array}{l}\text { Group } \\
3\end{array}$ & $\begin{array}{l}\text { Ethanol } \\
\text { +Metformin low } \\
\text { dose (Day 1-21) }\end{array}$ & Met-1 & $\begin{array}{l}125 \\
\mathrm{mg} / \mathrm{kg} / \mathrm{d} / \mathrm{po}\end{array}$ \\
\hline $\begin{array}{l}\text { Group } \\
4\end{array}$ & $\begin{array}{l}\text { Ethanol } \\
\text { +Metformin } \\
\text { moderate dose } \\
\text { (Day 1-21) }\end{array}$ & Met-2 & $\begin{array}{l}250 \mathrm{mg} \\
/ \mathrm{kg} / \mathrm{d} / \mathrm{po}\end{array}$ \\
\hline $\begin{array}{l}\text { Group } \\
5\end{array}$ & $\begin{array}{l}\text { Ethanol } \\
\text { +Metformin high } \\
\text { dose (Day 1-21) }\end{array}$ & Met-3 & $\begin{array}{l}500 \\
\mathrm{mg} / \mathrm{kg} / \mathrm{d} / \mathrm{po}\end{array}$ \\
\hline
\end{tabular}

All the treatments were given once a day for 21 days. All the groups were administered ethanol $40 \%$ in the dose of $1 \mathrm{ml} / 100 \mathrm{gm} /$ day to every day for 21 days by oral route. ${ }^{6}$ Group 2 animals were administered distilled water as vehicle for Metformin orally every day for 21 days. On $22^{\text {nd }}$ day, the animals were anesthetized and blood was collected by retro-orbital puncture to assess various biochemical marker enzymes and histopathological study. Later the animals were sacrificed by cervical dislocation. The liver was removed and the weight and volume were also recorded. Then, the liver was also dissected and cut into two parts. One part of liver embedded in $10 \%$ formalin solution and histopathological assessment of liver damage was performed. The other parts of livers were collected in TC 199 media in the tissue sample bottles and were taken to biochemistry laboratory to assess oxidative stress marker enzymes malondialdehyde (MDA), superoxide dismutase (SOD), catalase (CAT) spectrophotometrically. With the help of homogenizer, specified buffers and following standard procedures liver tissue homogenates were prepared. The cell homogenate then was centrifuged at $3000 \times \mathrm{g}$ for $10 \mathrm{~min}$ at $4^{\circ} \mathrm{C}(\mathrm{Remi}$ Industries Ltd, Remi Laboratory Instruments, Cooling Centrifuge, C-24 BL is low volume high speed model in table top design) to remove debris and nuclei. The supernatant which consists of cytosolic and mitochondrial fractions was stored at $-80^{\circ} \mathrm{C}$. They were used for determination of MDA, SOD, and CAT activities using UV Visible spectrophotometer, Model Lambda 35, Manufactured by Perkin Elmer Inc. USA. ${ }^{14-16}$ 


\section{Histopathological assessment}

The liver damage was assessed by histopathological scoring (HPS) on day 22 in all groups. Small portions of the liver was dissected and fixed in $10 \%$ formalin solution for $24 \mathrm{~h}$. The fixed tissues were embedded in paraffin, sectioned to 3-5 $\mu \mathrm{m}$ thickness, deparaffinized, and rehydrated using standard techniques. The extent of alcohol-induced necrosis and steatosis was evaluated by assessing morphological changes in liver sections stained with hematoxylin and eosin using standard techniques.

The scoring system comprised various histological features and it suggests the extent of liver injury.

\section{Histopathological scoring of liver damage ${ }^{7}$}

1. Portal fibrosis (PF: 0-6).

2. Lobular infiltration and Necrosis (LIN: 0-3).

3. Mallory bodies (MB: 0-3).

4. Hepatocyte ballooning (HB: 0-3).

5. Perisinusoidal Fibrosis (PSF: 0-3).

6. Fatty changes (FC: 0-3).

Addition of all scores was taken as "Total Score" of histopathological $(\mathrm{HPS}=$ Histo-Pathology Score $)$ parameter for one animal. Higher score indicated more liver damage (Range from 0 in normal to 21 with maximum damage).

\section{Statistical analysis}

All the data were expressed as mean \pm SD. The results were evaluated using One Way ANOVA Nonparametric- Kruskal Wallis test, Post test- Dunns (Compare all pairs of columns) using Graph Pad Prism -5 software.

Table 2: Histopathological scoring.

\begin{tabular}{|ll|}
\hline Scores $\mathbf{0}$ to $\mathbf{6}$ for portal fibrosis (PF) \\
\hline 0 & Indicates no abnormality \\
\hline 1 to 2 & Mild injuries \\
\hline 3 to 4 & Moderate injury \\
\hline 5 to 6 & Severe liver injury \\
\hline Scores $\mathbf{0}$ to 3 for other & parameters \\
\hline 0 & No abnormality \\
\hline 1 & Mild \\
\hline 2 & Moderate \\
\hline 3 & Severe liver injury \\
\hline
\end{tabular}

\section{RESULTS}

Table 3: Effect of Metformin on MDA, SOD and CAT levels in liver tissue of ethanol-induced hepatic dysfunction in rats.

\begin{tabular}{|c|c|c|c|}
\hline Groups (Symbol) & MDA (nmol/g) & SOD (nmol/g) & CAT (nmol/g) \\
\hline Group $1(\mathrm{E})$ & $12.27 \pm 1.22$ & $1.33 \pm 0.10$ & $25.9 \pm 1.13$ \\
\hline Group 2 (E+DW) & $11.91 \pm 0.78$ & $1.58 \pm 0.13^{\$}$ & $27.45 \pm 1.81$ \\
\hline Group 3 (Met-1) & $10.41 \pm 0.92^{\$}$ & $2.64 \pm 0.27^{\$ \$ \$, @ @ @ ~}$ & $32.39 \pm 1.33^{\$ \$ \$, @ @ @ ~}$ \\
\hline Group 4 (Met-2) & $9.84 \pm 0.96^{\$ \$, @ @ @ ~}$ & $3.3 \pm 0.23^{\$ \$ \$, @ @ @, f \mathfrak{f}}$ & $35.29 \pm 1.97^{\$ \$ \$, @ @ @ ~}$ \\
\hline Group 5 (Met-3) & $6.9 \pm 0.65^{\$ \$ \$, @ @ @, £ £ f}$ & $4.34 \pm 0.33^{\$ \$ \$, @ @ @, £ £ £ ~}$ & $40.73 \pm 1.96^{\$ \$ \$, @ @ @, £ £ \in}$ \\
\hline
\end{tabular}

Nonparametric - Wilcoxan matched signed rank test. Values- mean \pm SD. $(\mathrm{n}=6)$ comparisons were made between ethanol vs. other groups ${ }^{\$}-\mathrm{P}<0.05$, ${ }^{\$ \$}$. $\mathrm{P}<0.01,{ }^{\$ \$ \$}-\mathrm{P}<0.001$; between Vehicle Vs Drugs ${ }^{\circledR}-\mathrm{P}<0.05$, ${ }^{\circledR}-\mathrm{P}<0.01,{ }^{\circledR @ @ ~}-\mathrm{P}<0.001$; between Met- 1 Vs Met- $2 /$ Met $-3^{\mathrm{f}}-\mathrm{P}<0.05,{ }^{\text {ff }}-\mathrm{P}<0.01,{ }^{\mathrm{fff}}$ $-\mathrm{P}<0.001$.

Table 4: Effect of Metformin on liver histopathology of ethanol-induced hepatic dysfunction in rats.

\begin{tabular}{|c|c|c|c|c|c|c|c|}
\hline $\begin{array}{l}\text { Groups } \\
\text { (Symbol) }\end{array}$ & PF: 0-6 & LIN: $\mathbf{0 - 3}$ & MB: $\mathbf{0 - 3}$ & HB: $\mathbf{0 - 3}$ & PSF : 0-3 & FC : $0-3$ & $\begin{array}{l}\text { Total scores } \\
\text { (HPS): } 0-21\end{array}$ \\
\hline Group $1(\mathrm{E})$ & $2.67 \pm 1.37$ & $1.67 \pm 0.52$ & $0.5 \pm 0.55$ & $2.0 \pm 0.63$ & $0.83 \pm 0.41$ & $1.5 \pm 0.84$ & $9.17 \pm 1.72$ \\
\hline $\begin{array}{l}\text { Group } 2 \\
\text { (E+DW) }\end{array}$ & $3.33 \pm 1.03$ & $1.67 \pm 0.52$ & $0.33 \pm 0.52$ & $1.67 \pm 0.82$ & $0.83 \pm 0.41$ & $1.5 \pm 0.55$ & $9.33 \pm 1.37$ \\
\hline $\begin{array}{l}\text { Group } 3 \\
\text { (Met-1) }\end{array}$ & $2.0 \pm 0.89$ & $1.33 \pm 0.82$ & -- & $1.33 \pm 0.52$ & $0.5 \pm 0.55$ & $1.0 \pm 0.63$ & $6.17 \pm 1.84^{\$, @ @ ~}$ \\
\hline $\begin{array}{l}\text { Group } 4 \\
\text { (Met-2) }\end{array}$ & $1.83 \pm 0.75$ & $0.83 \pm 0.75$ & -- & $0.83 \pm 0.75$ & $0.33 \pm 0.52$ & $\begin{array}{l}0.67 \pm 0.8 \\
2\end{array}$ & $4.5 \pm 1.76^{\$ \$ \$, @ @ @ ~}$ \\
\hline $\begin{array}{l}\text { Group } 5 \\
\text { (Met-3) }\end{array}$ & $0.83 \pm 0.75$ & $0.83 \pm 0.41$ & -- & $0.5 \pm 0.55$ & $0.33 \pm 0.52$ & $0.33 \pm 0.52$ & $\begin{array}{l}2.83 \pm 1.17^{\$ \$ \$,} \\
@ @, £ £\end{array}$ \\
\hline
\end{tabular}

One Way ANOVA - Nonparametric- Kruskal Wallis test, Post test- Dunns (Compare all pairs of columns).

Values- mean \pm SD. $(n=6)$ comparisons were made between ethanol vs. treatments ${ }^{\$}-\mathrm{P}<0.05, \$ \$-P<0.01$, ${ }^{\$ \$}-\mathrm{P}<0.001$; between

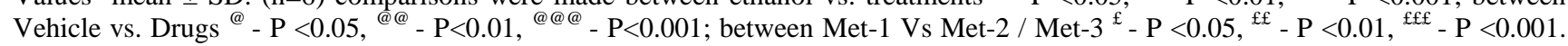


The liver tissue MDA, SOD and CAT levels were measured $(\mathrm{nmol} / \mathrm{g})$ in the various groups on day 22 and were compared within the different groups (Table 3). Among the three doses of Metformin, the highest dose $(500 \mathrm{mg} / \mathrm{kg})$ significantly reduced $(6.9 \pm 0.65 \mathrm{nmol} / \mathrm{g}, \mathrm{p}$ $<0.001)$ MDA levels and increased SOD (4.34 \pm 0.33 $\mathrm{nmol} / \mathrm{g}, \mathrm{p}<0.001)$ as well as CAT $(40.73 \pm 1.96 \mathrm{nmol} / \mathrm{g}$, $\mathrm{p}<0.001)$ levels when compared with only ethanol treated group, ethanol with vehicle treated and even lower doses of Metformin. Other two doses showed moderate anti-oxidant activity in terms of MDA, SOD and CAT levels when compared to only ethanol treated and ethanol with vehicle treated group.

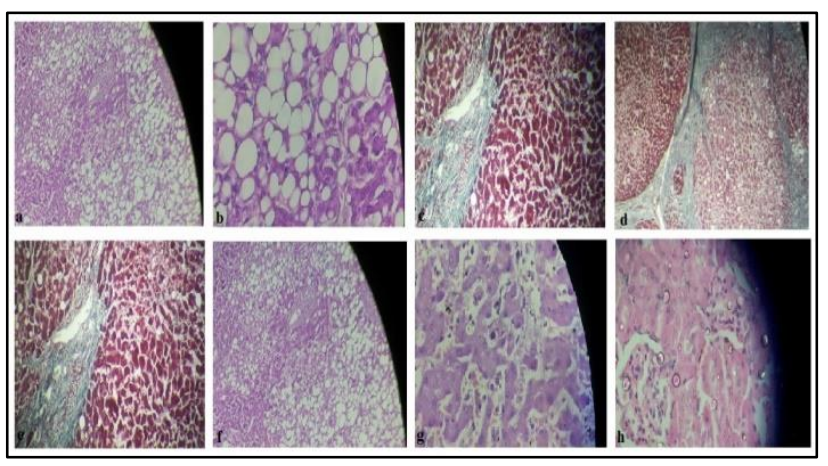

Figure 1: Morphological changes in liver sections stained with hematoxylin and eosin stain. (a)

Steatosis; (b) macrovescicular steatohepatitis; (c) fibrous bridge formation; (d) nodules and fibrous septa with effacement of the lobular architecture; (e) cirrhotic liver; (f) fatty liver; (g) necrosis and mallory bodies; (h) necrosis inflammation.

The liver damage was assessed by HPS on $22^{\text {nd }}$ day of the treatments and results are depicted in Table 4. The group treated with only ethanol showed highest HPS value $(9.17 \pm 1.72)$ indicated the severity of damage in rat hepatocytes. The HPS values of high dose metformin treatment group $(2.83 \pm 1.17, \mathrm{p}<0.001)$ were the lowest amongst the three metformin treatment groups. These observations suggested remarkable liver protection by metformin from alcohol induced injury. Other two doses also showed significantly lower histopathology scores in comparison to the ethanol and ethanol with methyl cellulose treated groups validated the protective activity of metformin in damaged rat hepatic cells by ethanol. The high dose metformin treatment group among the three groups showed lowest HPS value. Ethanol with vehicle; methyl cellulose treated group showed highest PF score $(3.33 \pm 1.03)$, indicated moderate injury and the lowest PF score $(0.83 \pm 0.75)$ is found in highest dose of metformin treated group, indicated no abnormality in rat liver structures. Only ethanol treated group has highest scores in other parameters, indicated mild/moderate liver injuries. All the metformin treated groups have zero MB score, suggested no mallory bodies found in hepatic tissues. Various abnormalities in hepatic tissue damaged by ethanol treatment observed in liver sections are presented in Figure 1.

\section{DISCUSSION}

Some scientists suggested alcoholic fatty liver disease is associated with various metabolic abnormalities. ${ }^{7,8}$ Some reports suggested the role of ethanol in oxidative stress which contributes to the pathogenesis of ALD. ${ }^{6}$ Ethanol induced oxidative stress leads to decrease fatty acid $\beta$ oxidation. This may lead to fatty liver-steatosis, hepatitis, cirrhosis. Metformin is an oral anti-diabetic drug, belongs to biguanide class, used in the treatment of type 2 diabetes mellitus, particularly, in overweight and obese people and with normal kidney function. Some researchers suggested the protective activity of metformin due to antioxidant effect. ${ }^{9}$

In the present study, $40 \%$ ethanol (Ethanol $40 \% \mathrm{v} / \mathrm{v} 1$ $\mathrm{ml} / 100 \mathrm{gm} / \mathrm{d}$, p.o.) daily for 21 days was used to induce ALD. The hepatic damage induced by ethanol was determined by oxidative stress marker enzymes malondialdehyde (MDA), superoxide dismutase (SOD), catalase (CAT) spectrophotometrically on the $22^{\text {nd }}$ day after first treatment and assessment of histopathological scores (HPS). Results of all the parameters were compared and analyzed statistically.

Metformin resulted antioxidant effect (in terms of biochemical parameters and histopathological study) in dose dependent manner in this study and a significant reduction of MDA levels in the group treated with ethanol and the highest dose (500 mg/kg/day/po) of metformin when compared with the groups treated with only ethanol and ethanol with vehicle for metformin. The decreased MDA levels suggested the protective action of metformin against oxidative stress. Similar results in MDA levels were reported previously by many researchers. ${ }^{10,11}$

The highest dose of metformin showed significant increase $(p<0.001)$ in SOD and CAT level when compared with other groups and lowest value of both the enzymes is found in only ethanol treated groups. Similar increase in SOD levels expressed the antioxidant property. $^{12}$

The liver damage was assessed by histopathological scoring (HPS) on $22^{\text {nd }}$ day in all groups considering various parameters. The scoring system comprised various histological features and it suggests the extent of liver injury. ${ }^{6,13}$ The total scores of the histopathological assessment was calculated for all groups and compared. Low HPS value was observed in metformin treated groups, whereas high HPS value was observed in ethanol treated and vehicle treated groups. Higher HPS values suggest liver damage in ethanol treated and vehicle treated groups. Whereas, low HPS value in metformin treated groups suggests anti ALD effect of metformin. Similarly, low HPS value was observed in low dose metformin treatment whereas high HPS value was observed in moderate and high doses of metformin. Pathological assessment is necessary for diagnosis of 
hepatic injury. Steatosis, lobular inflammation, and hepatocellular ballooning are the necessary components for the diagnosis of ALD. ${ }^{13}$

The total scores of the histopathological assessment was calculated for all groups and compared. Low HPS values were observed in metformin treated groups, whereas high HPS values were observed in ethanol treated and vehicle treated groups. Higher HPS values suggest liver damage in ethanol treated and vehicle treated groups. Whereas, low HPS values in metformin treated groups suggest antiALD effect of metformin.

\section{CONCLUSION}

This study shows protection offered by metformin treatment against liver damage caused by ethanol in rats. The overall results, suggest significant liver protection by metformin mediated through reduction in oxidative stress in a dose-dependent manner, which, also suggest highdose metformin may be a potential therapeutic candidate against the ALD. The recovery shown in liver structure in the groups treated with metformin is the evidence of hepatoprotection.

\section{ACKNOWLEDGMENTS}

Teaching and Non-teaching staff members of Department of Pharmacology, Pathology and Biochemistry for their kind co-operation and guidance. The authors also acknowledge the help of Central Animal House staff for help and maintenance of animals in the animal house.

Funding: No funding sources Conflict of interest: None declared

Ethical approval: The study was approved by the Institutional Animal Ethics Committee

\section{REFERENCES}

1. O'Shea RS, Dasarathy S, McCullough AJ. Alcoholic Liver Disease. Hepatology. 2010;51(1):307-28.

2. Rasineni K, Casey CA. Molecular mechanism of alcoholic fatty liver. Indian $\mathrm{J}$ Pharmacol. 2012;44(3):299-303.

3. Lieber CS. Metabolism of alcohol. Clin Liver Dis. 2005;9:1-35.

4. Corrao G, Torchio P, Zambon A, D'Amicis A, Lepore AR, di Orio F. Alcohol consumption and micronutrient intake as risk factors for liver cirrhosis: a case control study. Ann Epidemiol. 1998;8(3):1549.
5. Ostrowska J, Łuczaj W, Kasacka I, Rózański A, Skrzydlewska, E. Green tea protects against ethanol induced lipid peroxidation in rat organs. Alcohol. 2004;32(1):25-32.

6. Borole KD, Bodhankar SL. Preventive effect of malotilate on ethanol induced hepatic dysfunction in rats. Int J Pharm Bio Sci. 2014; 5(1):(P)151-7.

7. Borole KD, Bodhankar SL, Dawane JS, Kanwal JK. Hepatorenal repercussions of alcoholic exposure in a rat model: a dose-dependent study of metformin intervention. Iranian Biomed J. 2012;16 (2):101-6.

8. Acton QA, editor. Alcoholic Liver Diseases: Advances in Research and Treatment. 2011:4.

9. Nasri H, Rafieian-Kopaei M. Metformin: Current knowledge. J Res Med Sci. 2014;19(7):658-64.

10. Aliahmat NS, Noor MRM, Yusof WJW, Makpol S, Ngah WZW, Yusof YAM. Antioxidant enzyme activity and malondialdehyde levels can be modulated by Piper betle, tocotrienol rich fraction and Chlorella vulgaris in aging C57BL/6 mice. Clinics (Sao Paulo). 2012;67(12):1447-54.

11. Yayalacı Y, Celik I, Batı B. Hepatoprotective and antioxidant activity of linden (Tilia platyphyllos L.) infusion against ethanol-induced oxidative stress in rats. J Membr Biol. 2014;247(2):181-8.

12. Li S, Tan H-Y, Wang N, Zhang Z-J, Lao L, Wong C$\mathrm{W}$, et al. The Role of Oxidative Stress and Antioxidants in Liver Diseases. Int $\mathrm{J}$ Mol Sci. 2015;16:26087-124.

13. Takahashi Y, Fukusato T. Histopathology of nonalcoholic fatty liver disease/non-alcoholic steatohepatitis. World J Gastroenterol. 2014;20(42):15539-48.

14. Dahiru D and Obidoa O. Pretreatment of albino rats with aqueous leaf extract of Ziziphus mauritiana protects against alcohol-linduced liver damage Tropical Journal of Pharmaceutical Research. 2007;6(2):705-10.

15. Cleasby ME, Nicolas D, Hegarty BD, Cooney GJ, Kraegen EW. Metformin Prevents the Development of Acute Lipid-Induced Insulin Resistance in the Rat Through Altered Hepatic Signaling Mechanisms. Diabetes. 2004;53:3258-66.

16. Smith AC, Mullen KL, Junkin KA, Chabowski A. Metformin and exercise reduce muscle FAT/CD36 and lipid accumulation and blunt the progression of high-fat diet-induced hyperglycemia. Am J Physiol Endocrinol Metab. 2007;293:E172-81.

Cite this article as: Borole KD, Padalkar $\mathrm{PH}$, Swami R. Assessment of antioxidant activity of metformin in ethanol induced liver damage in Sprague Dawley rats. Int J Basic Clin Pharmacol 2016;5:324-8. 